\title{
Manufacturing of Bathroom Wall Tile Composites from Recycled Low-Density Polyethylene Reinforced with Pineapple Leaf Fiber
}

\author{
Negasi Gebremedhin and Gideon K. Rotich \\ Textile Manufacturing, Ethiopian Institute of Fashion Technology, Bahir Dar University, Ethiopia \\ Correspondence should be addressed to Gideon K. Rotich; rotichgideon@yahoo.com
}

Received 17 March 2020; Revised 5 May 2020; Accepted 9 May 2020; Published 4 June 2020

Academic Editor: Domenico Acierno

Copyright (c) 2020 Negasi Gebremedhin and Gideon K. Rotich. This is an open access article distributed under the Creative Commons Attribution License, which permits unrestricted use, distribution, and reproduction in any medium, provided the original work is properly cited.

\begin{abstract}
Plastic has been a dominant material for packaging in recent years but due to its nonbiodegradability, it is causing environmental pollution. Among the plastics used, low-density polyethylene is used abundantly. These plastics can be removed from the environment by recycling into useful products through reinforcing it with natural textile fibers into composite materials. Natural fiber-based composites are ecofriendly and low cost. This research is aimed at manufacturing composite wall tiles from recycled low-density polyethylene reinforced with pineapple leaf fibers (PALF). The PALF was extracted by the retting process followed by mechanical scratching and treated with $5 \% \mathrm{NaOH}$ to improve the fiber-matrix interaction. The composites were manufactured by the melt-mixing method followed by compression molding. The effects of fiber length and fiber weight proportion on composite properties were investigated using tensile, flexural, impact, and water absorption tests. The study showed that the optimum fiber weight proportion and fiber length for the optimal properties of the composite were achieved at $30 \%$ fiber weight proportion and $30 \mathrm{~mm}$ fiber length. The maximum tensile strength of $1562 \mathrm{~N} / \mathrm{mm}^{2}$, flexural strength of $454.9 \mathrm{~N} / \mathrm{mm}^{2}$, and impact strength of $225.2 \mathrm{~J} / \mathrm{mm}^{2}$ were obtained. Water absorption of the tiles increased with the increase in both the fiber weight proportion and the fiber length.
\end{abstract}

\section{Introduction}

Plastic materials are used widely for packaging drinks and household goods because of its versatility. However, due to its nonbiodegradable nature, it is affecting the environment through pollution. For this reason, there is an urgent need to remove the plastic waste from the environment. These plastics can be removed by burning, reusing, or recycling. Burning of the plastic waste produces hazardous fumes which are toxic, whereas reusing it is not an attractive alternative because of contamination. For this reasons, recycling to other products turns out to be a more attractive choice [1].Waste plastics can be chemically recycled in many ways such as glycolysis [2], hydrolysis, alkalosis, methanolysis, ammonolysis, and aminolysis $[3,4]$. A very attractive way of removing waste plastics is by mechanical recycling, which consist of gathering, shredding, and pelletizing followed by their reintroduction into the manufacturing of other plastic products. The recycled plastics can also be reinforced with either natural or synthetic textile fibers to manufacture load-bearing composite materials.

The interest in natural fiber-reinforced composite (NFRC) is increasing because of their properties of biodegradability, noncarcinogenicity, cost effectiveness, ecofriendliness, absence of health hazards, easy collection, and regional availability. They are also a renewable resource, thus providing a better solution for supply sustainability [5]. The NFRC versatile characteristics make it suitable for automobiles, railway coach, building construction, wall partition, cabinets, furniture, and packaging manufacture [6]. NFRC are viable because of the wide availability of natural fibers and agriculture by-product fibers which can be used as reinforcements [7]. Researchers have been working round the clock to find new sources of natural fibers that possess comparable physical and mechanical properties to synthetic fibers to be used in reinforcing of composites [8]. This is because synthetic fiber-reinforced polymers are costly and have an impact on the environment. Despite the advantages, natural fibers have 


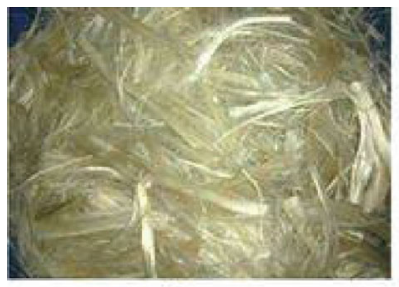

Jute

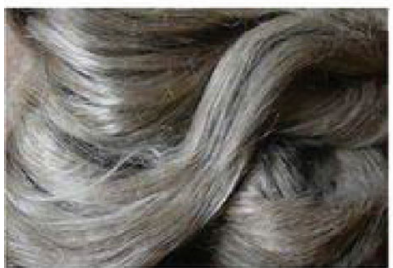

Flax

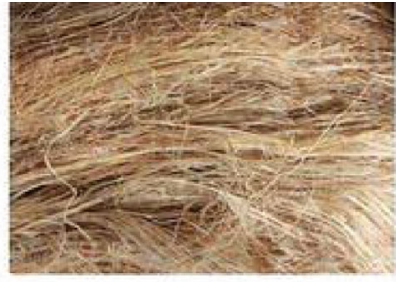

Hemp

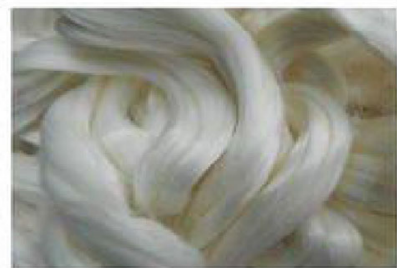

Ramie

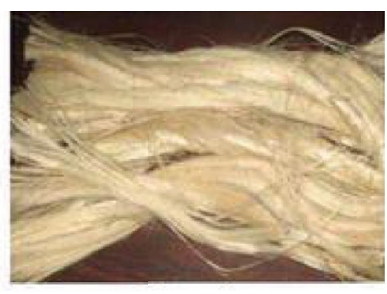

Kenaf

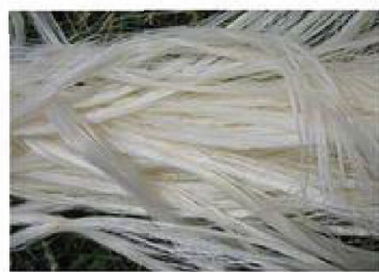

Sisal

FIGURE 1: Different type of natural fibers that can be used for composite reinforcement [14].

higher moisture absorption and they are hydrophilic in nature thus hampering composite fabrication. Moisture absorption swells and softens the fibers, thus adversely reducing their mechanical properties while its hydrophilic nature affects its dispersion/mixing within the matrix phase. For this reasons, natural fibers needs to be modified either physically or chemically to increase the interaction between the fiber and the polymer matrix. A number of studies have been done to solve this phenomenon $[9,10]$. Ali et al. [11] studied the effect of fluorocarbon and hydrocarbon on the mechanical properties and moisture regain of jute fiber-reinforced composite materials. They observe that the composites made with treated jute fiber regained very low moisture content as well as showed improved mechanical properties. Alix et al. [12] modified flax fibers with silane ( $\mathrm{Si}$ ) and styrene $(\mathrm{S})$ treatments and studied the water behaviour of their polyester composites. They observe that treatment increased the composites' moisture resistance. Bakri et al. [13] studied the effects of alkaline treatment on the mechanical, morphological, and spectral properties of banana fiber/epoxy composites and noted that treated fiber composites had superior properties.

There are a number of works done on natural fiberreinforced composites using fibers such as kenaf, oil palm, bamboo, jute, sisal, coconut, and pineapple leaf fibers as shown in Figure 1 [14]. Pineapple leaves are waste agricultural materials and can be used as a source of fibers [15]. Both the thermosets and thermoplastic resins have been used as matrices with these natural fibers. As a thermoplastic matrix material, low-density polyethylene (LDPE) has been extensively used with natural fibers for composite manufacture.

The development, mechanical properties, and uses of pineapple leaf fiber- (PALF-) reinforced polymer composites have been reviewed $[15,16]$. George et al. studied the mechanical properties of short PALF-reinforced LDPE composites prepared by melt mixing and solution mixing [17]. They evaluated the influence of fiber length, fiber proportion, and fiber orientation. Besides, fiber breakage and damage during processing were analysed using fiber distribution curve plus optical and scanning electron micrographs. PALF-epoxy composites have also been study by Jain et al. [18]. They prepared composites using the hand layup method and studied the effect of fiber proportion on the morphological, chemical, mechanical, and thermal properties of the composites. PALF have also been used to prepare polypropylene-based composites by twinscrew extrusion and deviation in fiber length, diameter, and aspect ratio induced by the mixing process analysed by Berzin et al. [19].

This research is aimed at using manually extracted PALF to reinforce recycled LDPE. The manufactured composites were evaluated for their tensile strength, flexural strength, impact resistance, and water absorption properties.

\section{Materials and Methods}

2.1. Materials. Recycled LDPE was sourced from Addis Ababa, while urea, sodium hydroxide, and acetic acid were sourced from the market and used without alteration. Pineapple leaves were collected from the southern parts of Ethiopia.

2.2. Extraction of Pineapple Leaf Fiber. The fibers were extracted from pineapple leaves using combined aqueous and mechanical methods. The leaves were scratched using a blunt blade to remove the waxy layer from its surface and immersed in urea solution for one week at room temperature. The urea solution was prepared by dissolving $10 \mathrm{~g} / \mathrm{l}$ of urea. Urea is an organic complex that is extremely soluble in water and nonpoisonous. It is frequently utilised as an enricher for the majority of the crops. It also encourages the development of microorganisms in soil and water. Urea escalates the wetting action of water and heightens the growth of microbes in water. Therefore, urea was used for fiber extraction in order to quicken the retting process [20, 21]. The leaves were removed and the fibers separated using a blunt knife by eliminating the leaf covers still attached to the fiber surface. The extracted fibers were washed with water and dried in air for 24 hours. 


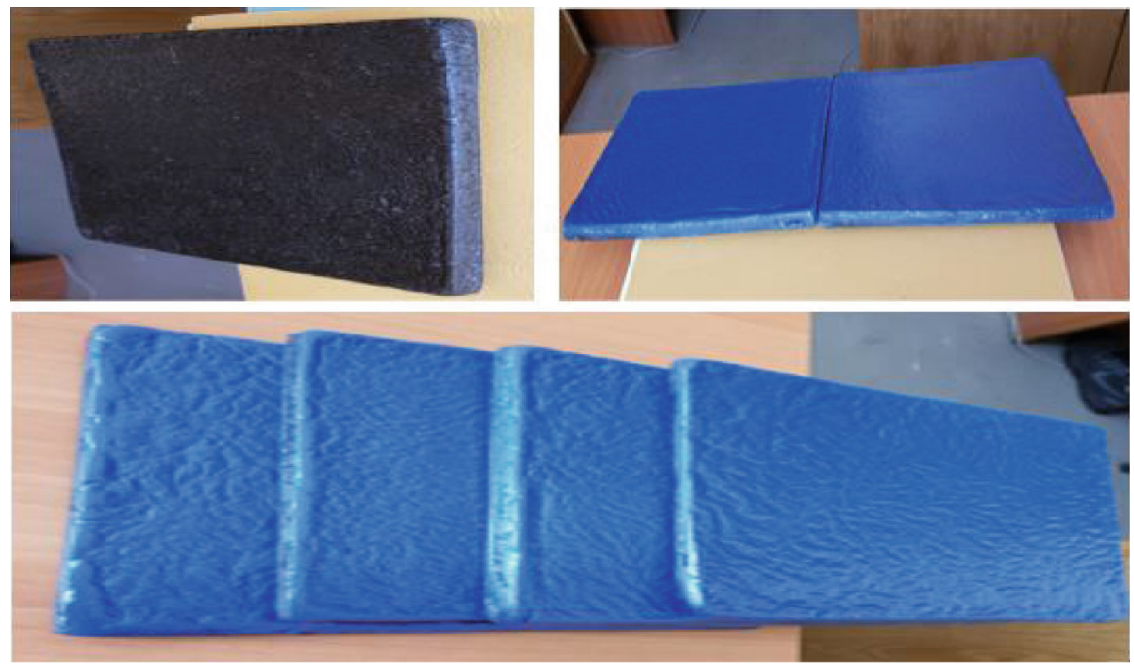

FIgURE 2: Pineapple fiber-reinforced low-density polyethylene composites.

2.3. Chemical Treatment of Pineapple Leaf Fiber. Prior to composite manufacture, the fibers were treated with sodium hydroxide solution in order to improve the fiber-matrix interface. The fibers were treated with $5 \% \mathrm{NaOH}$ solution for one hour at room temperature, after which they were washed several times and neutralised with acetic acid [22]. The fibers were dried in an air blast oven at a temperature of $60^{\circ} \mathrm{C}$ and stored in a dry environment ready for composite manufacture.

2.4. Fiber Testing. Tensile testing of extracted fibers were carried out in an Instron Universal Testing Machine Model 1121 at a crosshead speed of $1 \mathrm{~mm}$ per min. Specimens were prepared by mounting single fibers on a stiff cardboard piece with a $50 \mathrm{~mm}$ window. The ends of the fibers were fixed on the cardboard. The diameters of the extracted fibers were measured using an optical Leica microscope. Since the diameter of the fibers varies at different sections, an average of ten readings was taken for diameter determination. Moisture content of the fiber was also evaluated according to the ASTM D 1909-13 test standard.

2.5. PALF-LDPE Composite Preparation. Randomly oriented PALF-LDPE composites with varying fiber length and fiber weight proportion were manufactured by the melt-mixing process. The parameters used were a mixing time of $8 \mathrm{~min}$, rotor speed of $60 \mathrm{rpm}$, and mixing temperature of $130^{\circ} \mathrm{C}$ based on an early work by George et al. [17]. The temperature of $130^{\circ} \mathrm{C}$ was used because it does not affect the fiber properties. Composite tiles of size $200 \times 150 \times 8 \mathrm{~mm}$ were prepared using a closed mold. The mold was polished with a release agent to avoid LDPE from sticking to it. The process involved melting of the shredded LDPE, adding predetermined proportion of the chopped fibers, melt-mixing thoroughly to form a homogeneous viscous solution, and placing it into the prepared mold. Finally, the mold was closed and the samples were cooled down to room temperature under 12.5 $\mathrm{MPa}$ pressure for $30 \mathrm{~min}$. The specimens of the tiles pro-
TABle 1: Properties of extracted pineapple leaf fibers.

\begin{tabular}{lc}
\hline Properties & Values \\
\hline Average length $(\mathrm{mm})$ & 300.5 \\
Average diameter $(\mu \mathrm{m})$ & 59.73 \\
Moisture content $(\%)$ & 12 \\
Tensile strength $(\mathrm{cN} / \mathrm{Tex})$ & 32.679 \\
Elongation at break $(\%)$ & 2.08 \\
\hline
\end{tabular}

duced were shaped by sandpaper and used for testing as shown in Figure 2.

\subsection{Composite Tests}

2.6.1. Tensile Test. Tensile tests were performed on Instron 5567 at a cross-head speed of $50 \mathrm{~mm} / \mathrm{min}$. The samples were prepared for this test according to the ASTM D638 test standard (type II). At the beginning of the tensile test, the specimen elongates and the resistance of the specimen increases which was detected using a load cell. This value was recorded until the specimen fractured, and five samples were tested.

2.6.2. Flexural Test. Flexural strength is the combination of tensile strength and compressive strength. The tests were done on a universal testing machine. The specimens were prepared according to the ASTM D790 test standard with dimension $200 \times 30 \times 8 \mathrm{~mm}$. The specimens were tested on a support span of $130 \mathrm{~mm}$ as per the standard.

2.6.3. Impact Test. Charpy impact tests on unnotched specimens were performed using a pendulum impact testing machine JBS-300 N model. The test specimens were prepared according to the ASTM D6110-18 test standard with a dimension of $50 \mathrm{~mm}$ long, and a cross-sectional area of $24 \mathrm{~mm}^{2}$. Five specimens were tested and an average value was reported. 
TABLE 2: Properties of the manufactured composite.

\begin{tabular}{|c|c|c|c|c|c|c|}
\hline Run & $\begin{array}{c}\text { Factor } 1 \\
\text { A: fiber proportion } \\
(\%)\end{array}$ & $\begin{array}{c}\text { Factor } 2 \\
\text { C: fiber length } \\
(\mathrm{mm})\end{array}$ & $\begin{array}{c}\text { Response } 1 \\
\text { Tensile strength } \\
\left(\mathrm{N} / \mathrm{mm}^{2}\right)\end{array}$ & $\begin{array}{c}\text { Response } 2 \\
\text { Flexural strength } \\
\left(\mathrm{N} / \mathrm{mm}^{2}\right)\end{array}$ & $\begin{array}{c}\text { Response } 3 \\
\text { Impact strength } \\
\left(\mathrm{J} / \mathrm{mm}^{2}\right)\end{array}$ & $\begin{array}{c}\text { Response } 4 \\
\text { Water absorption } \\
(\%)\end{array}$ \\
\hline 1 & 30 & 10 & 1129.2 & 353.6 & 146.594 & 1.38 \\
\hline 2 & 10 & 10 & 803.6 & 152.6 & 132.842 & 1.20 \\
\hline 3 & 20 & 3.18 & 755.6 & 123.2 & 113.92 & 1.26 \\
\hline 4 & 36.82 & 20 & 784.8 & 134.44 & 123.09 & 5.52 \\
\hline 5 & 20 & 30 & 1002.4 & 225.5 & 136.602 & 1.44 \\
\hline 6 & 30 & 20 & 1209.8 & 397.24 & 165.436 & 3.96 \\
\hline 7 & 36.82 & 36.82 & 783.4 & 133.78 & 126.72 & 4.43 \\
\hline 8 & 30 & 30 & 1893 & 585.64 & 256.494 & 2.64 \\
\hline 9 & 3.18 & 30 & 655.4 & 85.252 & 91.288 & 2.22 \\
\hline 10 & 10 & 30 & 864 & 280 & 125.652 & 1.57 \\
\hline 11 & 20 & 20 & 975.4 & 349.7 & 142.14 & 2.50 \\
\hline 12 & 30 & 36.82 & 1305.8 & 455 & 195.682 & 6.59 \\
\hline 13 & 10 & 3.18 & 655.2 & 115.06 & 102.15 & 1.09 \\
\hline 14 & 3.18 & 20 & 533.2 & 64.64 & 85 & 1.07 \\
\hline 15 & 20 & 36.82 & 975.2 & 283.06 & 134.45 & 1.37 \\
\hline
\end{tabular}

2.6.4. Water Absorption Test. Water absorption tests were carried out in accordance with the ASTM D570 test standard. Samples of each composite type were oven dried before its weight was recorded as the initial weight of the composites. The samples were then placed in distilled water maintained at room temperature $\left(25^{\circ} \mathrm{C}\right)$ for 24 hours. The samples were then removed from water, dried with a cotton fabric, and weighed. The amount of water absorbed by the composites (in percentage) was calculated using equation (1):

$$
\% \mathrm{~W}=\frac{\left(W_{t}-W_{o}\right)}{W_{o}} \times 100
$$

where $W_{t}$ is the weight of the composite after immersion in water and $W_{o}$ is the weight of a dried sample.

\section{Results and Discussion}

3.1. Characterization of PALF. The physical and mechanical properties of the extracted PALF are shown in Table 1.

3.2. Characterization of the Manufactured Composites. From the experiments, the mechanical and water absorption properties of the manufactured composite are shown in Table 2. By using the design of experiment software, the properties of the fiber proportions not tested were extrapolated as also reported in Table 2.

\subsection{Tensile Strength}

3.3.1. Effect of Fiber Weight Proportion on Tensile Strength. As seen in Figure 3, the tensile strength of the composite increased with the increase in fiber weight (weight.) proportion from $10 \%$ to $30 \%$ and from $800 \mathrm{~N}$ to $1200 \mathrm{~N}$, respectively, but after $30 \%$ fiber proportion, the strength decreased. In

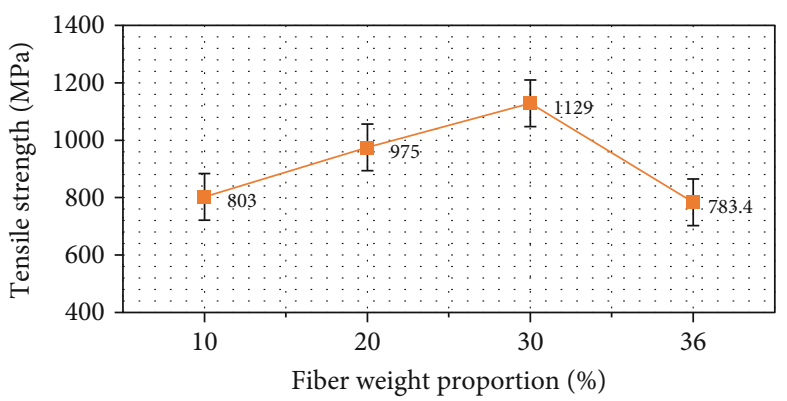

FiguRE 3: Effect of fiber weight proportion on tensile strength.

other words, the addition of 20 weight. \% of PALF increased the strength of the composite by almost 50\%. From observation, the optimum fiber proportion which yields the highest tensile strength was at $30 \%$. This increase of strength means that the reinforced LDPE became stiff and could withstand higher load. The fiber served as reinforcement because the major share of load was taken up by the fibers [23]. Besides, at fiber weight. \% greater than $30 \%$, the fibers were excessive; therefore, the matrix LDPE was not enough to flow through and wet each and every fiber thus leaving voids and the fibers were easily expose to environmental degradation. The interfacial adhesion between fiber and LDPE was not good at these levels of weight proportion as shown in Figure 4. Fiber agglomerations occurs thus causing fiber dispersion problems in LDPE, which led to a decrease in tensile strength [17].

3.3.2. Effect of Fiber Length on Tensile Strength. The strength of fiber-reinforced composites depends on the degree to which an applied load is transferred by the matrix to the reinforcing fibers. The extent of load transfer is a function of fiber 


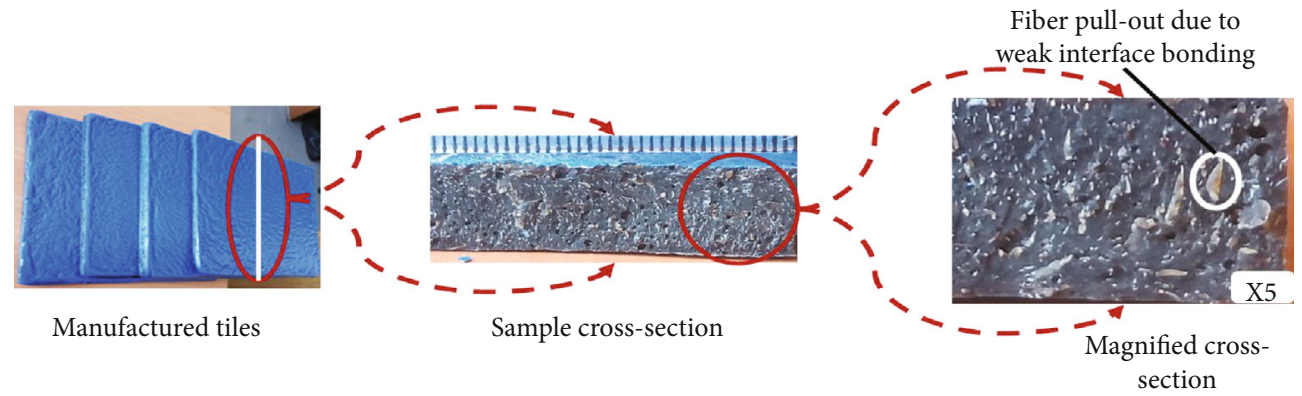

Figure 4: Sample cross-sectional area.

length and magnitude of fiber-matrix interfacial bond. In short-fiber-reinforced composites, there exists a critical fiber length that is required for the fiber to develop its fully stressed condition in the matrix. If the fiber is shorter than this critical length, the stressed fiber will be pulled out from the matrix and the composite will fail at a lower stress. When the length is greater than the critical length, the stressed composites will lead to breaking of fibers and a higher composite strength. From Figure 5, it can be seen that as the fiber length increased from 10 to $30 \mathrm{~mm}$, there is an enhancement in composite strength due to the increase in stress transfer between the matrix and fiber. When the fiber length is increased beyond $30 \mathrm{~mm}$, there is reduction in tensile strength. This indicates that the mechanical properties are reduced beyond $30 \mathrm{~mm}$ fiber length. The reduction could be associated with poor dispersion of fiber in the matrix and fiber to fiber entanglements at a higher fiber length [6].

\subsubsection{Effect of Fiber Weight Proportion as a Function of Fiber} Length on Tensile Strength. As seen in Figure 6, the tensile strength of the PALF-reinforced LDPE composite increased with an increase in both fiber weight proportion and fiber length up to $30 \%$ and $30 \mathrm{~mm}$, respectively. At this point, the optimal tensile strength was achieved, but above this value any increase in one factor or in both resulted in a reduction in tensile strength due to the formation of the fiber-to-fiber interaction rather than the fiber-to-polymer interaction. In addition, if the fiber length is above $30 \mathrm{~mm}$, there is a chance of fiber entanglement within the composite which can result in a significant reduction in its tensile strength.

\subsection{Flexural Property}

3.4.1. Effect of Fiber Weight Proportion on Flexural Strength. The flexural strength for PALF-LDPE composite is shown in Figure 7. From the figure, the flexural strength increased gradually with the increase in fiber weight proportion. An increase in fiber weight content from 10 to $30 \%$ on weight increased the flexural strength by about $42 \%$. This could be due to more fibers being present on a given composite cross-section to carry the load at a higher fiber weight \%. However, further increase in fiber weight content above this value resulted in the lowering of flexural strength. The decrease in flexural strength at higher fiber weight proportion may be due to the dispersion problems during melt-spinning [23].

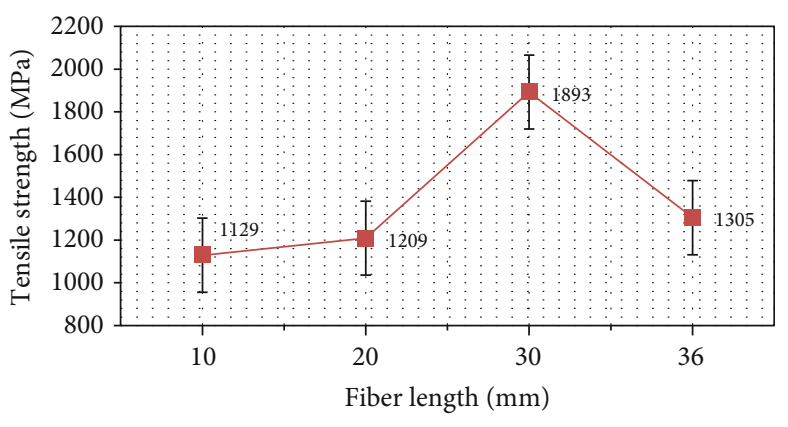

Figure 5: Effect of fiber length on tensile strength.

3.4.2. Effect of Fiber Length on Flexural Strength. The reliance of composite flexural properties on fiber length is shown in Figure 8. The same trend of higher flexural strength is shown with fiber length of $30 \mathrm{~mm}$ when compared to the fibers which are shorter and also fibers which are above $30 \mathrm{~mm}$ composites. The flexural strength of the PALF composites containing $30 \mathrm{~mm}$ long fibers was $65 \%$ higher than that of PALF composites with $10 \mathrm{~mm}$ length fiber. The optimum flexural strength and modulus of the PALF composites were obtained at a fiber length of $30 \mathrm{~mm}$. Similar results were reported by Devi et al. where the flexural strength of the composite containing $30 \mathrm{~mm}$ long fibers was $25 \%$ higher than that of composites containing of $5 \mathrm{~mm}$ length [6].

3.4.3. Effect of Fiber Weight Proportion as a Function of Fiber Length on Flexural Strength. From Figure 9, the variation of flexural strength with fiber weight proportion and fiber length combined can be seen. From the figure, the flexural strength values of the PALF-LDPE composites were found to increase with both increments in fiber weight $\%$ and fiber length. The optimum flexural strength was achieved at 30\% fiber weight proportion and $30 \mathrm{~mm}$ length of fiber. The increase in flexural strength was significantly affected by the increase in fiber weight \% rather than the increase in fiber length as shown by the gradient of the increase.

\subsection{Impact Strength}

3.5.1. Effect of Fiber Weight Proportion on Impact Strength. Figure 10 depicts the Charpy impact strength (CIS) of unnotched samples of treated PALF composites with fiber weight proportion varying from 10 to $30 \%$. CIS increased 


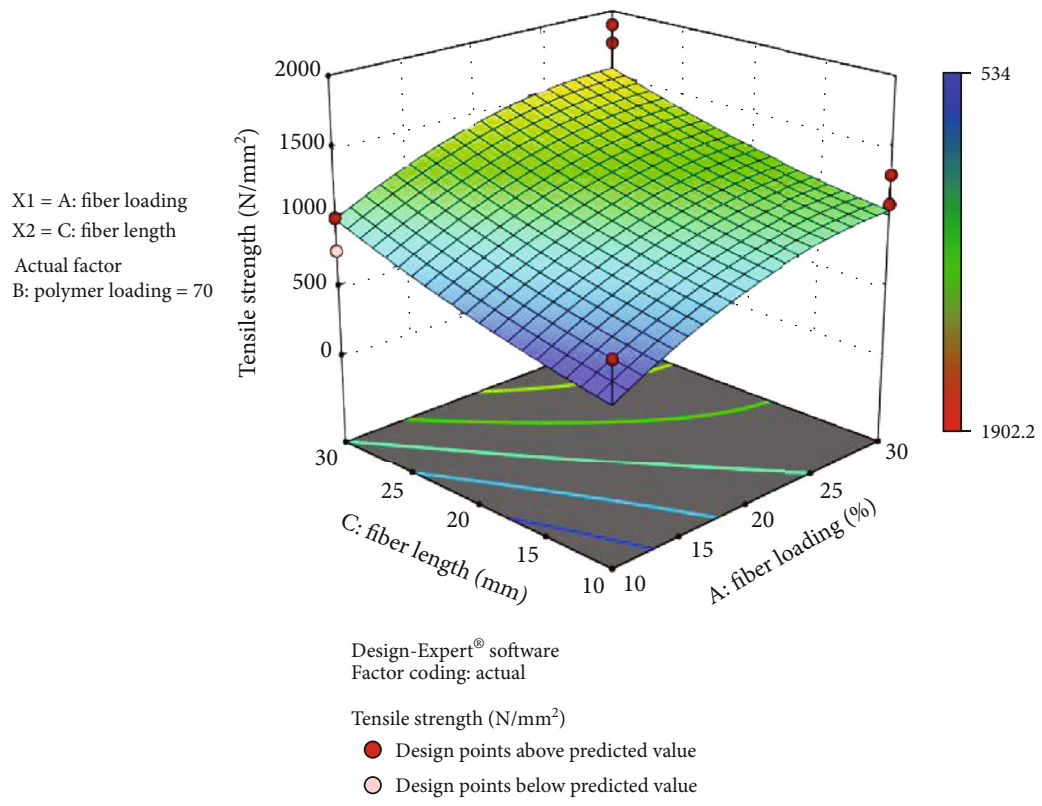

FIGURE 6: Effect of fiber weight proportion as a function of fiber length on tensile strength.

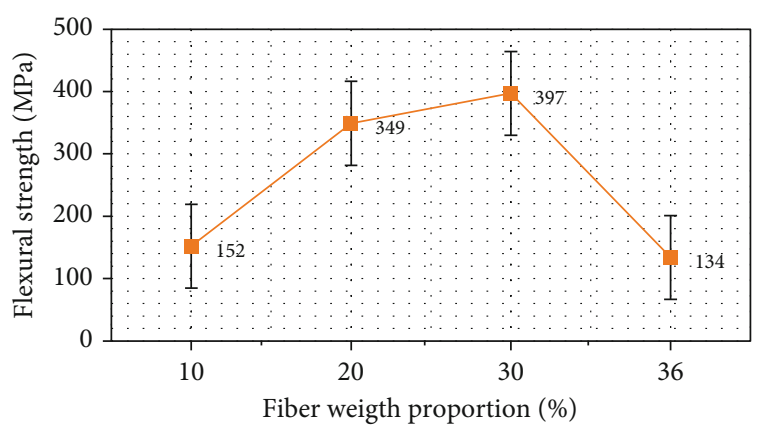

FiguRE 7: Effect of fiber weight proportion on flexural property.

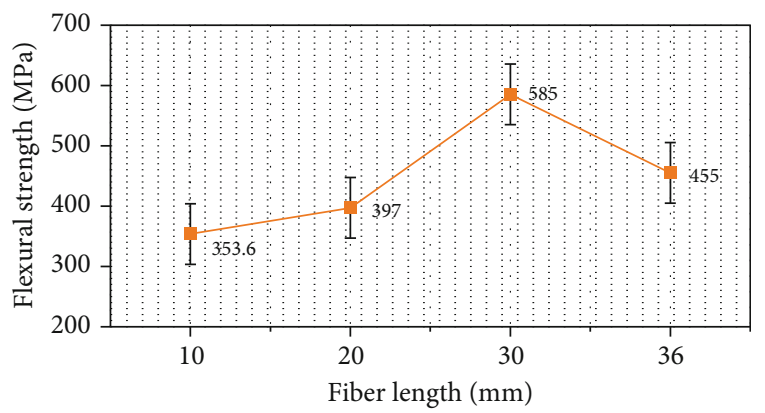

Figure 8: Effect of fiber length on flexural strength.

with the amount of fibers added until a reduction was reached above 30\% fiber weight. At this fiber weight \%, the CIS value was about $20 \%$ more than that of the $10 \%$ fiberreinforced LDPE as the fiber bridge cracks and increases the resistance of its propagation. However, at higher percentage of fiber weight $\%$ above the optimal percentage (30 weight $\%$ ), the CIS decreased than the 30 weight $\%$ since addition of more fibers creates regions of stress concentrations that require comparatively less energy to initiate a crack as seen in Figure 4.

Piah et al. [24] reported that the energy-absorbing mechanism of composites during fracture includes the utilisation of energy required to debond the fibers and pull them completely out of the matrix due to weak interface strength between the fiber and matrix. In practical interest, a significant part of energy absorption during impact takes place through the fiber pull-out, matrix crack, and fiber breakage.

3.5.2. Effect of Fiber Weight Proportion as a Function of Fiber Length on Impact Strength. The work of fracture (impact strength) of PALF-LDPE composites at 30\% proportion as a function of fiber length is shown in Figure 11. It is seen that comparatively higher impact strength is observed for composites of fiber length $30 \mathrm{~mm}$ (critical fiber length). In fact, there was a decrease in impact strength for composites of higher fiber length (i.e., $>30 \mathrm{~mm}$ ).

In most fiber-filled composites, a significant part of the energy absorption during impact takes place through the fiber pull-out process. The energy involved and, hence, toughness is higher when the length of the fibers is equal or greater to the critical length (lc). Fibers shorter than lc $(30 \mathrm{~mm})$ will be pulled out from the matrix rather than being broken when a crack passes through the composite. The fracture energy will then be basically a combination of the work necessary to debond the fibers out of the matrix and the work done against friction in pulling the fibers out of the matrix as shown in Figure 4. In a similar manner, when the fiber length is above the critical length $(30 \mathrm{~mm})$, the impact strength of the composite is decreased due to weak surface interaction. It requires less energy to overcome the fiber-fiber interaction 
$\mathrm{X} 1=\mathrm{C}$ : fiber length

$\mathrm{X} 2=\mathrm{A}$ : fiber loading

Actual factor

B: polymer loading $=70$

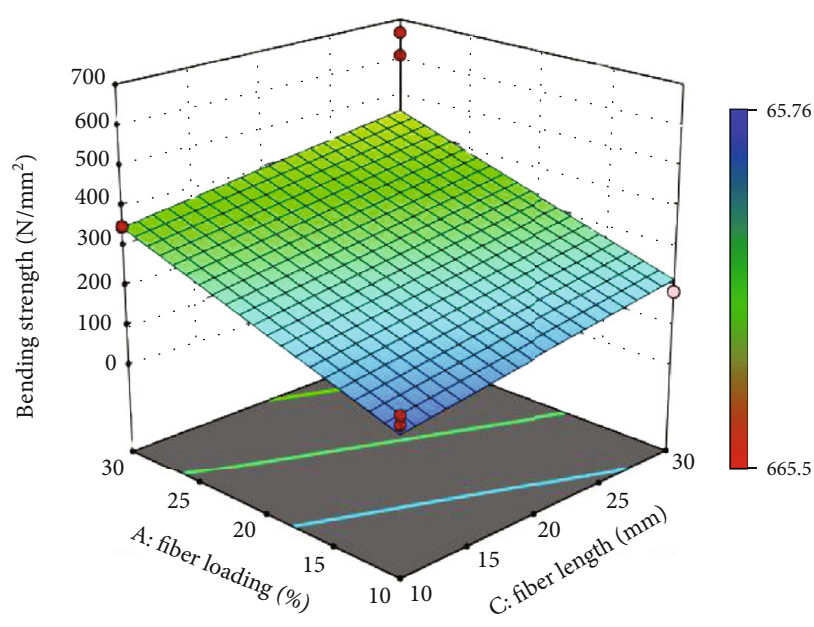

Design-Expert ${ }^{\circledR}$ software

Factor coding: actual

Bending strength $\left(\mathrm{N} / \mathrm{mm}^{2}\right)$

Design points above predicted value

$\bigcirc$ Design points below predicted value

FiguRE 9: Effect of fiber proportion as a function of fiber length on flexural strength.

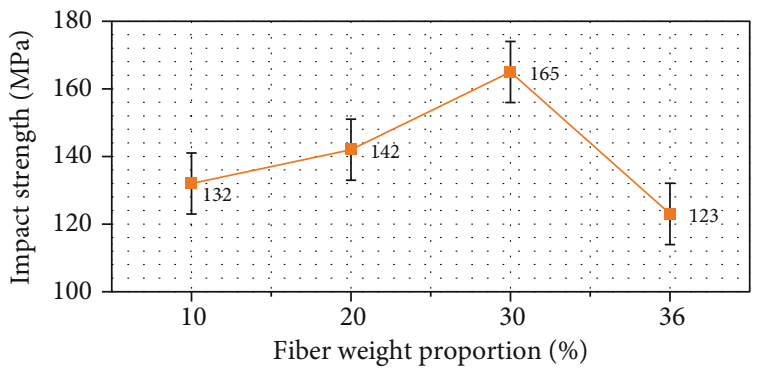

Figure 10: Effect of fiber weight proportion on impact strength.

rather than the fiber-polymer interaction; therefore, it exhibits lower impact strength. The weak surface adhesion between the fiber and the matrix initiated the crack up on the energy transferred to the composite. As reported by Chong et al. [25], impact strength decreases due to poor interfacial bonding between the fiber and the matrix.

\subsection{Water Absorption}

3.6.1. Effect of Fiber Weight Proportion as a Function of Fiber Length on Water Absorption. All lignocellulosic fibers have low resistance to water absorption due to the presence of $\mathrm{OH}$ groups in its chemical structure. After $24 \mathrm{~h}$ immersion in water, there was a noticeable effect of fiber content on water absorption test results as shown in Figure 12. The lowest water absorption rate was achieved with $10 \%$ fiber weight proportion. There was only a slight reduction in the rate of water absorption when the length of the fiber was increased from $10 \mathrm{~mm}$ to $30 \mathrm{~mm}$. When the volume of the fiber increased from $10 \%$ to $30 \%$, the rate of water absorption also increased because more lignocellulosic fibers are added into the composite, meaning that more hydrogen bonds were formed between the water molecules and $\mathrm{OH}$ group in the fibers. The same results were observed by Huner et al. who reported that the rate of water absorption increased with the increase in fiber content $[26,27]$. This was due to the formation of less surface interaction between the matrix and fiber when mixed together giving higher water absorption [28].

\section{Conclusion}

The results of this study showed that a useful composite with good properties can be successfully manufactured by reinforcing waste LDPE with treated PALF. The optimum length of the fiber required to obtain PALF-LDPE composites of maximum properties was found to be $30 \mathrm{~mm}$. The tensile strength of PALF-LDPE composites increased drastically up to the optimum level of fiber weight proportion. But, in the case of flexural strength, it increased linearly with the weight fraction and fiber length up to the optimal level of $30 \%$ fiber weight proportion and $30 \mathrm{~mm}$ fiber length, beyond which there was reduction in the flexural strength. The impact strength also increased linearly with the fiber weight proportion. The composite with 30 weight $\%$ fiber content exhibited an impact strength of $225.2 \mathrm{~J} / \mathrm{mm}^{2}$. The amount of water absorbed by the composites increases with the increase in the PALF weight proportion due to the formation of interaction between the $\mathrm{OH}$ groups in fibers and water. Therefore, the optimal mechanical and water absorption properties were achieved at $30 \%$ fiber proportion and $30 \mathrm{~mm}$ fiber length. The manufactured composites showed improved mechanical properties with respect to the fiber proportion increase, showing the reinforcement potential of PALF. It is thus possible to envision a prospective industrial use of this agricultural waste, for instance, for the manufacture of bathroom wall tiles. 
$\mathrm{X} 1=\mathrm{A}$ : fiber loading $\mathrm{X} 2$ = C: fiber length

Actual factor

B: polymer loading $=70$

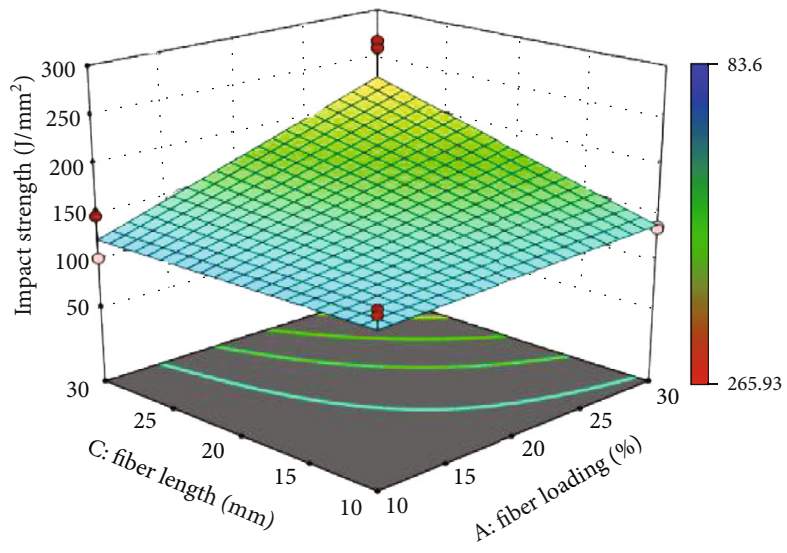

Design-Expert ${ }^{\circledR}$ software

Factor coding: actual

Impact strength $\left(\mathrm{J} / \mathrm{mm}^{2}\right)$

- Design points above predicted value

Design points below predicted value

FIgURE 11: Effect of fiber proportion as a function of fiber length on impact strength.
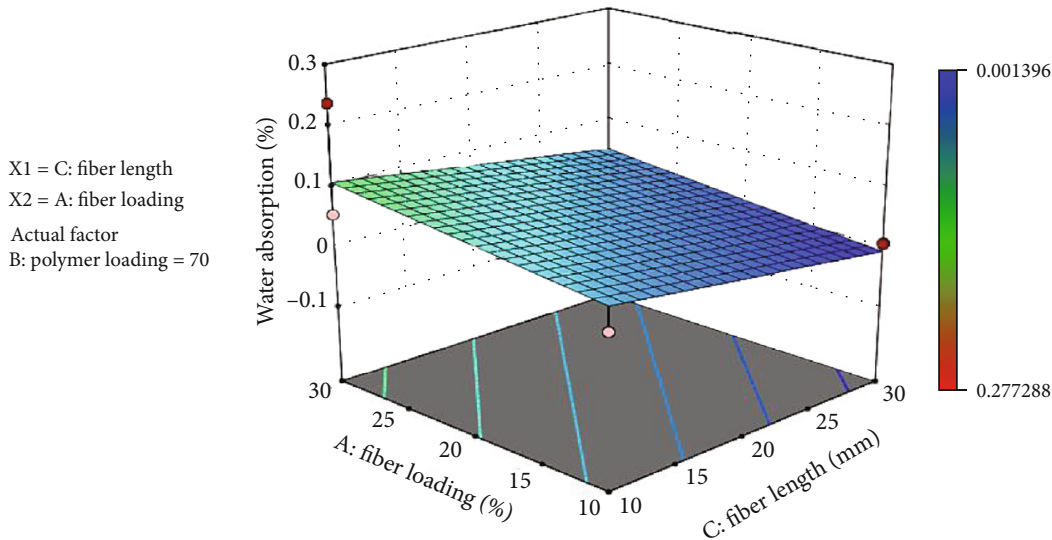

Design-Expert ${ }^{\circledR}$ software

Factor coding: actual

Water absorption (\%)

Design points above predicted value

Design points below predicted value

FIGURE 12: Effect of fiber weight proportion as a function of fiber length on water absorption.

\section{Data Availability}

All relevant data to the manuscript have been included.

\section{Conflicts of Interest}

The authors declare that they have no conflicts of interest.

\section{Acknowledgments}

The authors acknowledge the financial support from the post graduate office of Ethiopian Institute of Textile and Fashion Technology Bahir Dar University.

\section{References}

[1] J. M. L. Reis, R. Chianelli-Junior, J. L. Cardoso, and F. J. V. Marinho, "Effect of recycled PET in the fracture mechanics of polymer mortar," Construction and Building Materials, vol. 25 , no. 6, pp. 2799-2804, 2011.

[2] E. S. Barboza, D. R. Lopez, S. C. Amico, and C. A. Ferreira, "Determination of a recyclability index for the PET glycolysis," Resources, Conservation and Recycling, vol. 53, no. 3, pp. 122128, 2009.

[3] A. M. Al-Sabagh, F. Z. Yehia, G. Eshaq, A. M. Rabie, and A. E. ElMetwally, "Greener routes for recycling of polyethylene terephthalate," Egyptian Journal of Petroleum, vol. 25, no. 1, pp. 53-64, 2016. 
[4] V. Sinha, M. R. Patel, and J. V. Patel, "Pet waste management by chemical recycling: a review," Journal of Polymers and the Environment, vol. 18, no. 1, pp. 8-25, 2010.

[5] L. Yan, N. Chouw, and X. Yuan, "Improving the mechanical properties of natural fibre fabric reinforced epoxy composites by alkali treatment," Journal of Reinforced Plastics and Composites, vol. 31, no. 6, pp. 425-437, 2012.

[6] L. U. Devi, S. S. Bhagawan, and S. Thomas, "Mechanical properties of pineapple leaf fiber-reinforced polyester composites," Journal of Applied Polymer Science, vol. 64, no. 9, pp. 1739-1748, 1997.

[7] V. P. Cyras, S. Iannace, J. M. Kenny, and A. Vázquez, "Relationship between processing and properties of biodegradable composites based on PCL/starch matrix and sisal fibers," Polymer Composites, vol. 22, no. 1, pp. 104-110, 2001.

[8] N. M. Barkoula, S. K. Garkhail, and T. Peijs, "Biodegradable composites based on flax/polyhydroxybutyrate and its copolymer with hydroxyvalerate," Industrial Crops and Products, vol. 31, no. 1, pp. 34-42, 2010.

[9] A. Ali, K. Shaker, Y. Nawab et al., "Hydrophobic treatment of natural fibers and their composites-a review," Journal of Industrial Textiles, vol. 47, no. 8, pp. 2153-2183, 2016.

[10] M. H. Ameer, K. Shaker, M. Ashraf et al., "Interdependence of moisture, mechanical properties, and hydrophobic treatment of jute fibre-reinforced composite materials," The Journal of the Textile Institute, vol. 108, no. 10, pp. 1768-1776, 2017.

[11] A. Ali, K. Shaker, Y. Nawab et al., "Impact of hydrophobic treatment of jute on moisture regain and mechanical properties of composite material," Journal of Reinforced Plastics and Composites, vol. 34, no. 24, pp. 2059-2068, 2015.

[12] S. Alix, L. Lebrun, C. Morvan, and S. Marais, "Study of water behaviour of chemically treated flax fibres-based composites: a way to approach the hydric interface," Composites Science and Technology, vol. 71, no. 6, pp. 893-899, 2011.

[13] M. K. B. Bakri, E. Jayamani, and S. Hamdan, "Processing and characterization of banana fiber/epoxy composites: effect of alkaline treatment," Materials Today: Proceedings, vol. 4, no. 2, pp. 2871-2878, 2017.

[14] S. Taj, M. A. Munawar, and S. Khan, "Natural fiber-reinforced polymer composites," Proceedings of the Pakistan Academy of Sciences, vol. 44, no. 2, p. 129, 2007.

[15] R. M. N. Arib, S. M. Sapuan, M. A. M. M. Hamdan, M. T. Paridah, and H. M. D. K. Zaman, "A literature review of pineapple fibre reinforced polymer composites," Polymers and Polymer Composites, vol. 12, no. 4, pp. 341-348, 2018.

[16] M. Asim, K. Abdan, M. Jawaid et al., "A review on pineapple leaves fibre and its composites," International Journal of Polymer Science, vol. 2015, Article ID 950567, 16 pages, 2015.

[17] J. George, S. S. Bhagawan, N. Prabhakaran, and S. Thomas, "Short pineapple-leaf-fiber-reinforced low-density polyethylene composites," Journal of Applied Polymer Science, vol. 57, no. 7, pp. 843-854, 1995.

[18] J. Jain, S. Jain, and S. Sinha, "Characterization and thermal kinetic analysis of pineapple leaf fibers and their reinforcement in epoxy," Journal of Elastomers \& Plastics, vol. 51, no. 3, pp. 224-243, 2019.

[19] F. Berzin, T. Amornsakchai, A. Lemaitre, E. di Giuseppe, and B. Vergnes, "Processing and properties of pineapple leaf fibers-polypropylene composites prepared by twin-screw extrusion," Polymer Composites, vol. 39, no. 11, pp. 41154122, 2018.
[20] R. Bora and T. Padmini, "Fiber extraction from Calotropis gigantea stem with different retting methods and its comparision," IJCS, vol. 7, no. 3, pp. 144-150, 2019.

[21] R. K. Dhanalaxmi and J. V. Vastrad, "Influence of retting methods on quality of mesta fibres," Indian Journal of Natural Products and Resources, vol. 4, no. 2, pp. 178-183, 2013.

[22] S. Mishra, M. Misra, S. S. Tripathy, S. K. Nayak, and A. K. Mohanty, "Potentiality of pineapple leaf fibre as reinforcement in PALF-polyester composite: surface modification and mechanical performance," Journal of Reinforced Plastics and Composites, vol. 20, no. 4, pp. 321-334, 2016.

[23] P. S. Mukherjee and K. G. Satyanarayana, "Structure and properties of some vegetable fibres," Journal of Materials Science, vol. 21, no. 1, pp. 51-56, 1986.

[24] M. R. M. Piah, A. Baharum, and I. Abdullah, "Mechanical properties of bio-composite natural rubber/high density polyethylene/mengkuang fiber (NRHDE/MK)," Polymers and Polymer Composites, vol. 24, no. 9, pp. 767-774, 2018.

[25] C. Lane, A. Ishak, A. Ibrahim, and H. Dahlan, "Effects of rice husk modification with liquid natural rubber and exposure to electron beam radiation on the mechanical properties of NR/HDPE/rice husk composites," Sains Malaysiana, vol. 40, no. 9, pp. 985-992, 2011.

[26] U. Huner, "Effect of water absorption on the mechanical properties of flax fiber reinforced epoxy composites," Advances in Science and Technology Research Journal, vol. 9, no. 26, pp. 1-6, 2015.

[27] W. Z. W. Zahari, R. N. R. L. Badri, H. Ardyananta, D. Kurniawan, and F. M. Nor, "Mechanical properties and water absorption behavior of polypropylene / ijuk fiber composite by using silane treatment," Procedia Manufacturing, vol. 2, pp. 573-578, 2015.

[28] H. N. Dhakal, Z. Y. Zhang, and M. O. W. Richardson, "Effect of water absorption on the mechanical properties of hemp fibre reinforced unsaturated polyester composites," Composites Science and Technology, vol. 67, no. 7-8, pp. 1674-1683, 2007. 